\title{
Radioimmunoassays Of Hormonal Changes Associated With Dysphoric Disorder In Premenstrual Women
}

\author{
Ragab H. EL-Yamani* and Maha G. Soliman** \\ * Obstetric and Gynecology Dept. Faculty of Medicine, Al-Margab University, Great \\ Socialist People's Libyan Jamahiriya and ** Pharmacology Dept (Medical microbiology \\ and immunology unit) Notional Organization for Drug Control and Research
}

\begin{abstract}
The neuroendocrinological changes that occur in patients with Premenstrual Dysphoric Disorder (PMDD) are poorly understood. The mechanism is likely to be a complex interaction between gonadal hormones and neurotransmitters. Melatonin is the predominant pineal neurohormone. The gonadal changes associated with melatonin are mediated via the hypothalamus. The purpose of this study was to evaluate melatonin concentrations in patients with PMDD. Also serum prolactin (PRL) and progesterone levels were estimated for any correlation with melatonin secretion. During the symptomatic late luteal phase, serum melatonin concentrations were determined by Radioimmunoassay (RIA) in 12 women with PMDD and 12 normal control women (NC). Also serum PRL and progesterone were estimated to all women by RIA. Melatonin concentration in patient with PMDD was significantly lower than in NC (mean 25.25 VS 79.25 P $\leq 0.05$ ). Serum PRL levels were significantly higher in PMDD subjects than in NC (mean 39.08 VS $20.17 \mathrm{P} \leq 0.05$ ). Serum progesterone levels were lower in PMDD than NC (mean 20.42 VS $33.58 \mathrm{P} \leq 0.05$ ). The results showed inverse correlation between melatonin and PRL levels $(\mathrm{r}=0.931, \mathrm{P} \leq 0.001)$ and direct correlation between melatonin and progesterone levels $(\mathrm{r}=0.894, \mathrm{p} \leq 0.001)$. No correlation was found between PRL and progesterone level. Findings of the study suggest that lowered melatonin levels in women with PMDD may be due to involvement of the pineal gland in the pathogenesis of this disorder.
\end{abstract}

\section{Introduction}

It is well known that clinical symptoms such as psychosis, epileptic seizures and sleep disturbances aggravate around the time of menstruation. In some healthy women, subjective sleep feelings or moods have been reported to change throughout the menstrual cycle, which suggests that sleep structure and sleep-wake rhythm may change during the menstrual cycle (Ito et al., 1995).

Premenstrual Dysphoric Disorder (PMDD) is the new terminology used in the American Psychiatric Association's
Diagnostic and Statistical Manual of Mental Disorders (DSM-IV). It more rigorously defines criteria for what historically has been referred to as premenstrual syndrome. Based on studies of its phenomenology and course, PMDD was categorized in DSM-IV as a depressive mood disorder (Parry, 1997).

Although the etiology of this condition has remained elusive despite considerable research, recent success in treatment studies would seem to 
indicate progress. Efficacy has been shown both by drugs, which inhibit ovulation, and those, which directly interact with the central nervous system (CNS). The mechanism is therefore likely to be a complex interaction between gonadal hormones and neurotransmitters (melatonin and serotonin) with changes in the CNS initiated by fluctuating ovarian activity. The neuroendocrinological changes that occur in these patients are poorly understood (Su et al., 1997).

The pineal gland is an active neuroendocrine organ that responds to photic hormonal stimuli. Pineal activity can be viewed as the net balance between hormone and neuron mediated influences. It contains receptors for the active sex hormones and prolactin (Reiter, 1991). Melatonin is the predominant pineal neurohormone. It circulates in the blood like a classical hormone and affects distant target organs, especially the neuroendocrine centers of the CNS. In the absence of light at night an increase in melatonin biosynthesis in the pineal gland is stimulated by electrical signals originating from neurons in the suprachiasmatic nuclei. These neurons inputs from the lateral eyes (Reiter, 1989). Melatonin receptors have been identified in the human nucleus supra-chiasmaticus, which is the master circadian pacemaker (Reppert et al., 1988).

The gonadal changes associated with melatonin are mediated via the hypothalamus and suggest a general suppressive effect on GnRH pulsatile secretion and reproductive function (Silman, 1991).

The aim of this study was to replicate and extend previous work in which the authors observed lower melatonin secretion during the luteal phase in PMDD patients compared to control subjects. Prolactin and progesterone levels were estimated for any correlation between them and melatonin concentration.

\section{Subjects And Methods:}

The study included 12 patients who met DSM-IV criteria for PMDD and 12 apparently healthy control subjects (NC). All volunteers were between the ages of 25-35 years, nonsmokers, resided in Cairo, with similar socioeconomic level and had not traveled in the 8 weeks prior to the study. All volunteers attended to ElZahraa Hospital, Faculty of Medicine for Girls, Al-Azhar University. Measurements were made during symptomatic luteal menstrual cycle phases in PMDD patients. Samples were collected in the morning time (8$10 \mathrm{am})$ and within the same season (from January 1998 to March 1998). According to Molina et al., (1996) single morning blood sample $(5 \mathrm{ml})$ was collected from each patient. Sera were obtained by centrifugation of the clotted blood samples, divided into 3 aliquots and stored at $-20^{\circ} \mathrm{C}$ until assayed in the allowed time for melatonin, progesterone and prolactin (Yoshkor et al ., 2000; Och et al .,2000). Both progesterone and prolactin levels were determined by Radioimmunoassay (RIA) using Cota-A-Count kits supplied by (Diagnostic Products Corporation, Los Angeles, CA, USA). Serum melatonin levels were determined also by RIA technique using the kit supplied by INRA, Nouzilly, France.

Statistical analysis and data presentation of the results were carried out by the use of the software Microsoft Excel 5.0 (1994), Microsoft Corporation, USA and according to Shwartz, (1980) for IBM Computers. 


\section{Results}

The results of the present investigation could be summarized as in table (1) :

Figure (1). Illustrates the significances changes of serum melatonin level between the control group and the PMDD groups. It was found that the serum melatonin levels during luteal phase, was significantly lower in patients with PMDD than that of the normal control group. On contrast, serum prolactin levels were significantly higher $(\mathrm{P} \leq 0.05)$ in
PMDD women than the normal control ( mean 39.08 VS 20.17) fig (2) .

Concerning the progesterone level during the luteal phase in patients fig (3) showed a significant lower concentration $(\mathrm{p} \leq 0.05)$ than in normal subjects ( mean 20.42 VS 33.58. $\mathrm{p} \leq 0.05$ ).

Fig (4) showed inverse correlation between melatonin and PRL levels $(r=$ $0.931, \mathrm{p} \leq 0.01$ ) while fig (5) illustrated the direct correlation between melatonin and progesterone levels $(\mathrm{r}=$ $0.894, \mathrm{p} \leq 0.001)$. On the other hand, no correlation was found between PRL and progesterone levels .

Table (1): The descriptive statistics of the PMDD subjects and the NC.

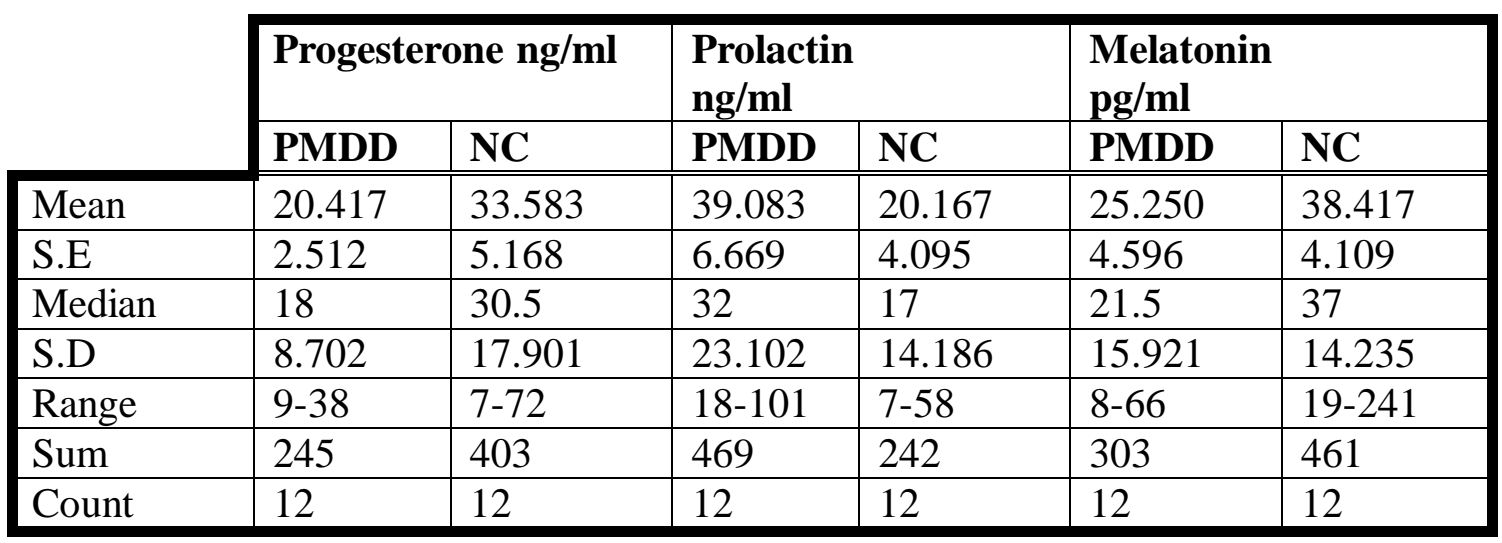

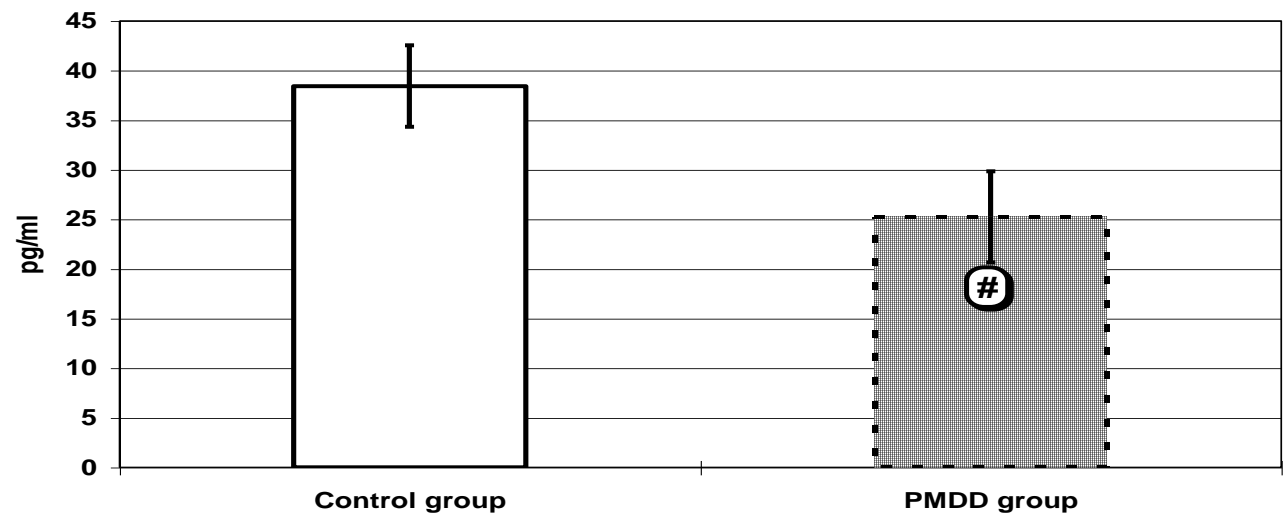

Fig. (1) : The significance change of serum melatonin level between the control and the PMDD group (mean ${ }_{ \pm}$S.E.). 


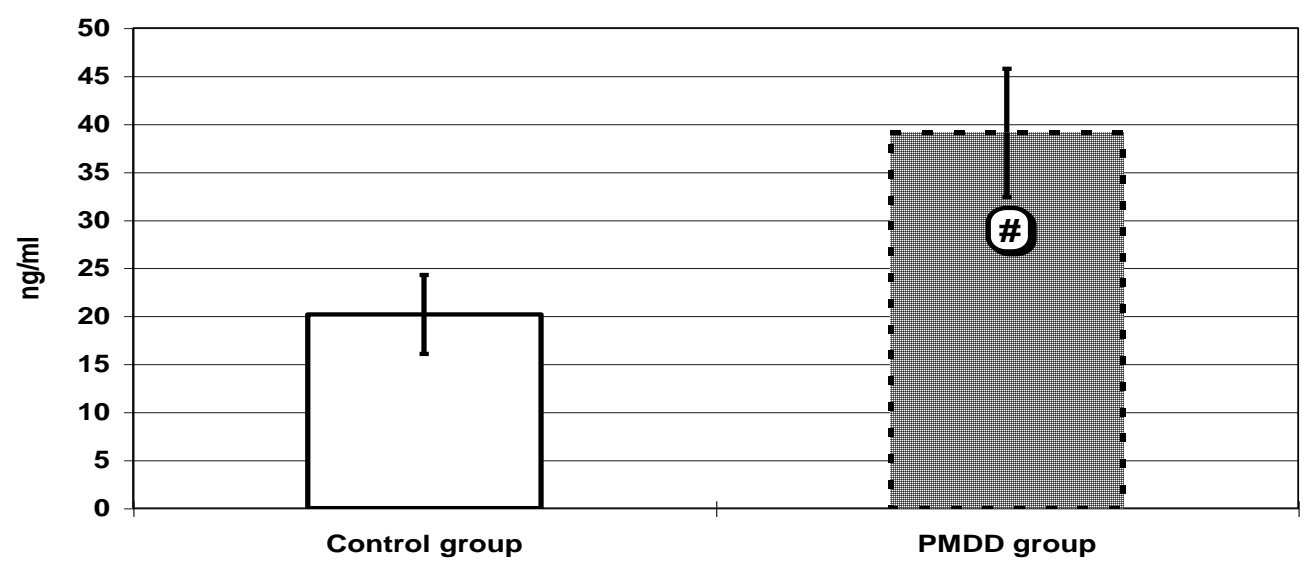

Fig. (2) : The significance change of serum prolactin level between the control and the PMDD group (mean \pm S.E.).

\# Significant change from control at $p \leq 0.05$

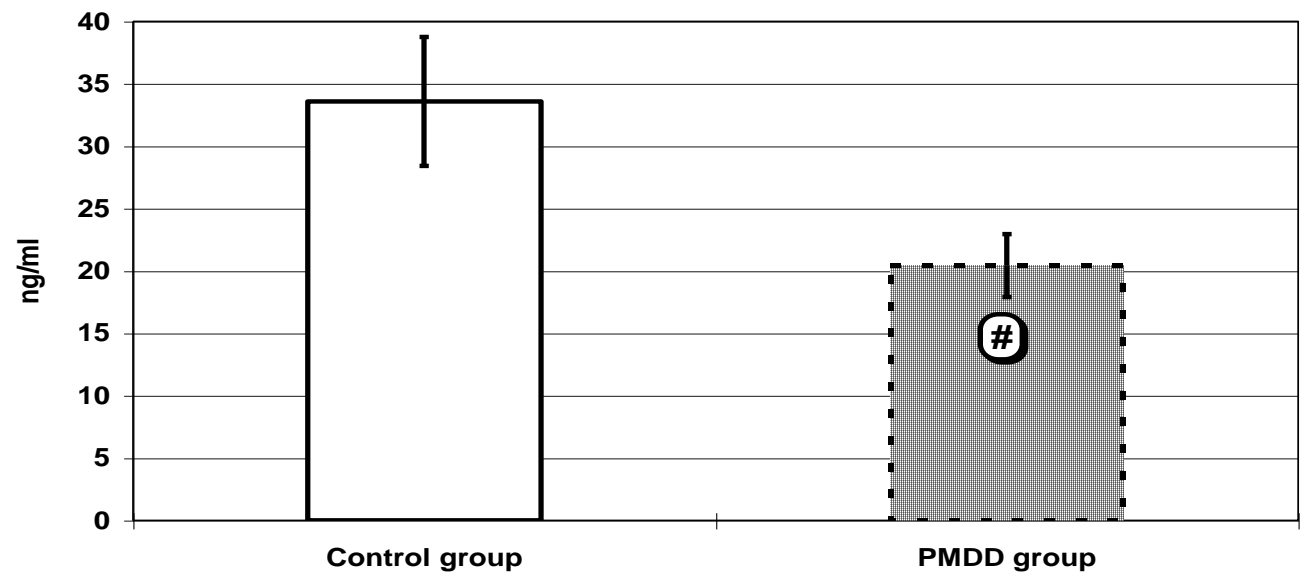

Fig. (3) : The significance change of serum progesterone level between the control and the PMDD group (mean \pm S.E.)

\# Significant change from control at $p \leq 0.05$

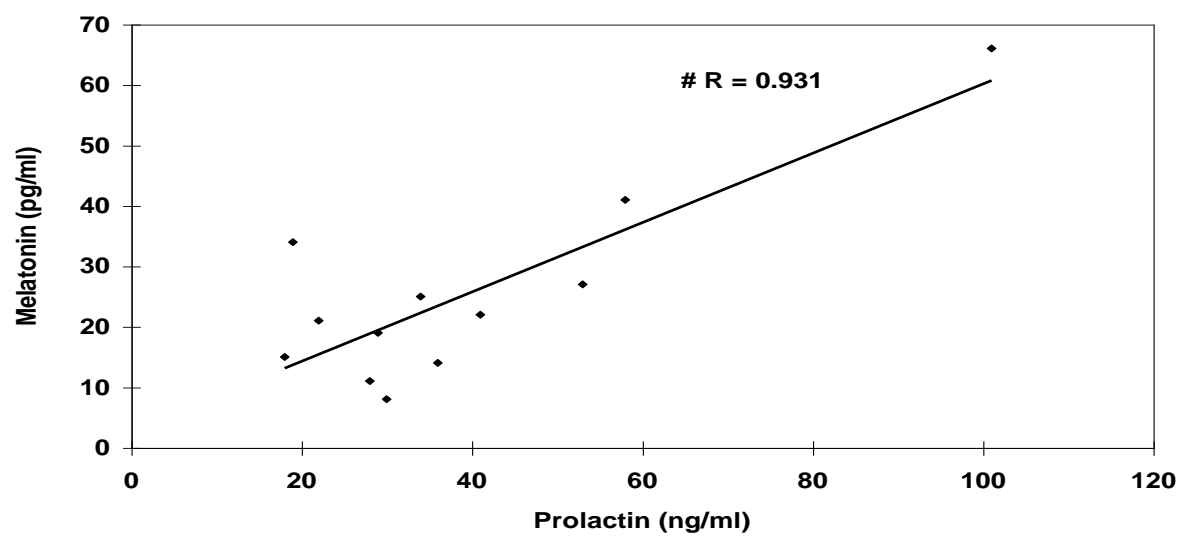

Fig. (4) : The correlation between serum melatonin and serum Prolactin in the PMDD group

\# Significant correlation at $p \leq 0.001$ 


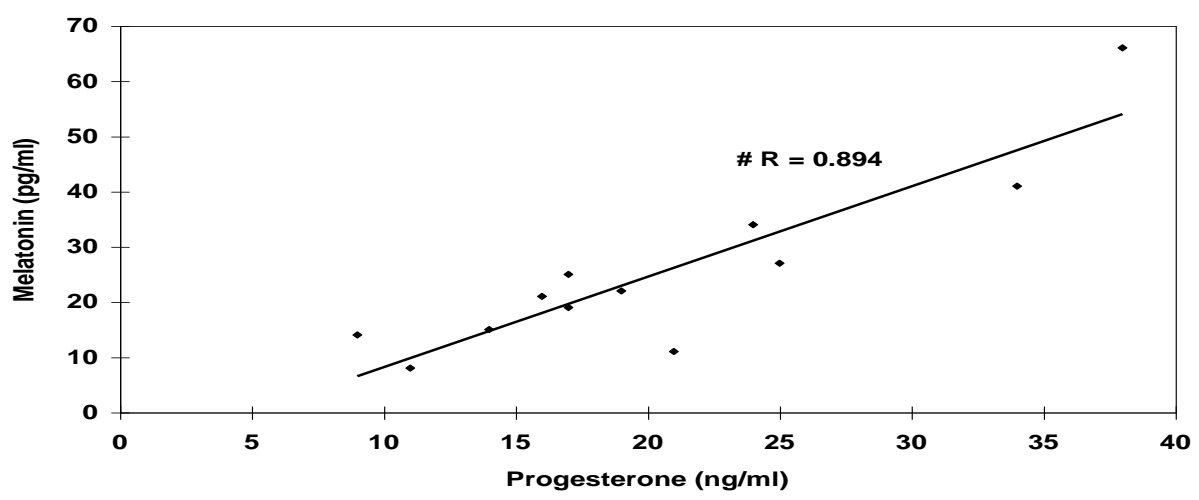

Fig. (5) : The correlation between serum melatonin and serum progesterone in the PMDD group

\# Significant correlation at $\mathbf{p} \leq \mathbf{0 . 0 0 1}$

\section{DISCUSSION}

In the present study it was found that the serum melatonin levels, measured during the symptomatic luteal phases were significantly lower in patients with PMDD than NC (mean 25.25 VS 79.25 $\mathrm{P} \leq 0.05$ ). These findings are in agreement with the findings of Parry et al. (1997) who reported that serum melatonin levels during the luteal phase were significantly lower in PMDD subjects than NC. They suggest that this observation do not likely represent a disturbance in pineal reactivity to suprachiasmatic nucleus efferent. Instead, the findings support a possible disturbance in PMDD in the clock itself or its coupling mechanisms. In another study by Parry et al. (1997), they reported that in PMDD subjects during the luteal phase, melatonin onset time was delayed, duration was compressed, and area under the curve, amplitude, and mean levels were decreased than NC subjects.

Murialdo et al. (1994) reported that the normal increase in urinary metabolism excretion during the luteal phase was less pronounced in the PMDD patients. They suggest impaired pineal function in PMDD.

Parry's findings support low serotonin and melatonin metabolism in PMDD compared with $\mathrm{NC}$, and an increasing number of rigorous studies report a reduction of symptoms with selective serotonin reuptake inhibitors (Parry, 1997).

The causal relationship, if any, between the decreased melatonin secretion and PMDD has not been established.
Preliminary data in rats and humans suggest that endogenous opioids augment melatonin secretion. Thus, it is possible that, withdrawal of endogenous opiods which has been found during the luteal phase (Facchinelti et al., 1987) induces suppression in melatonin secretion in PMDD subjects.

Data about women complaining of the PMDD are equally conflicting, some reports demonstrating significantly higher serum PRL concentrations both in the follicular and luteal phases, lower levels in the follicular phase, or no significant difference with control subjects (Magos and Studol, 1984).

In the present study it was noted that the serum PRL levels were higher in PMDD women than the NC (mean 39.08 VS $20.17 \mathrm{P} \leq 0.05$ ).

Rubinow and Schmidt (1992) reported excess prolactin secretion during the luteal phase in PMDD subjects than in NC. The present study showed significant correlation between melatonin and PRL levels $(r=0.931, P \leq 0.001)$. The results of Brzezinski et al. (1994) indicate that endogenous PRL do not affect the levels or circadian phase of melatonin. In vitro results showed that melatonin suppressed PRL secretion (Bhgat et al., 1994). In contrast to that Terzolo et al. (1993) reported that exogenous melatonin has a stimulatory effect on PRL release. Also Okatani et al. (1994) reported that oral melatonin administration induce a significant increase in serum prolactin concentration. They suggested that the stimulation is 
not mediated by opioids. Okatani and Sagara (1993) suggested that melatonin can regulate nocturnal PRL secretion independent of sleep-related factors.

Progesterone and certain of its metabolites are anxiolytic (Baker et al., 1995). Some studies have reported lower progesterone concentration during the luteal phase in some patients with PMDD (Munday et al., 1981). Other studies have not confirmed this observation (Taylor, 1979).

O'Brien et $\boldsymbol{a l}$. (1980) actually found elevated plasma progesterone levels following ovulation in PMDD sufferers. The present study showed a significant lower progesterone concentration during the luteal phase in patients with PMDD than NC subjects (mean 20.42 VS $33.58 \mathrm{P}$ $\leq 0.05$ ). No correlation was found between PRL and progesterone but a direct correlation was found between melatonin and progesterone $(\mathrm{r}=0.894, \mathrm{p} \leq 0.001)$

Brzezinski et al . (1994) reported that endogenous progesterone do not affect melatonin levels. Also Delfs et al. (1994) reported that there is no consistent change in melatonin blood concentrations in response to the varying endogenous or exogenous concentrations of sex steroids.

Regarding the effect of melatonin on progesterone, Sandyk et al. (1992) reported that melatonin stimulates progesterone production. This is in contrast to in vitro animal studies which indicate a suppressive effect of melatonin on progesterone production (Khan-Dawood and Dawood, 1993; Sirotkin, 1994).

\section{CONCLUSION:}

Serum melatonin levels, during the late luteal phase, were significantly lower in PMDD women than NC suggesting that the pineal gland involved in the pathogenesis of the PMDD. There was an inverse correlation between melatonin and PRL levels and direct correlation between melato-nin and progesterone levels. In future studies, attempts should be made to estimate and compare between serum melatonin levels, its metabolism and urinary excretion in patients with PMDD.

\section{References}

1. Baker E.R., Best R.G. and Fredi R.L. (1995): Efficacy of progesterone vaginal suppositories in alleviation of nervous symptoms in patients with premenstrual syndrome J. Assist. Reprod. Genet., 12: 205 - 209.

2. Bhagat L., Duraiswami S. and Muralidhar K. (1994): Mode of action of inhibin-like pineal antigonadotropin is different from melatonin during compensatory ovarian hypertrophy. J. Pineal. Res., 16(4): 193 -197.

3. Brzezinski A., Cohen M., Ever-Handi P., Mordel N., Schenker J.G. and Laufer N. (1994): The pattern of serum melatonin levels during ovarian stimulation for in vitro fertilization. Int. J. Fertil. Menopausal. 39(2): 81-85.

4. Delfs T.M., Baars S., Fock C., Schumacher M., Olcese J. and Zimmermann R.C. (1994): "Sex steroids do not alter melatonin secretion in the human". Hum. Reprod. 9(1): 4954.

5. Facchinetti F., Martignoni E. and Petraglia F. (1987): Premenstrual fall of plasma $\beta$-Erdorphin in patients with premenstrual syndrome. Fertil. Steril., 47: 570 - 573.

6. Ito M., Kohsaka N. and Honma K. (1995): Changes in biological rhythm and sleep structure during the menstrual cycle in healthy women. Seishin Shinkeigaku Zasshipsychiatria et Neurologia Japonica, 97 (3): 155-164.

7. Khan-Dawood F.S. and Dawood M.Y. (1993): Baboon corpus luteum: The effect of melatonin on in vitro progesterone production. Fertil-Steril., 59 (4): 896-900.

8. Magos A. and Studd J. (1984): The premenstrual syndrome In progress in obstet and Gryecal, Stud. J. (ed) p. 334

9. Molina C.A., Munoz H.A., Martin, G.J.A., Uberos F.J., Rodriguez C.T. and Acuna C.D. (1996): 5Methoxytryptophol and melatonin in children: differences due to age and sex. J. Pineal. Res., 21(2): 73 - 78.

10. Munday M., Brush M.G. and Taylor R.W. (1981): Correlations between 
progesterone, estradiol and aldosterone levels in the premenstrual syndrome. Clinical Endocrinology, 14: 1-9.

11. Murialdo G., Fonzi S., Costelli P., Solinas G.P., Parodi C., Marabini S., Fanciullacci M. and Polleri A. (1994): Urinary melatonin excretion throughout the ovarian cycle in menstrually related migraine. Cephalalgia , 14(3): 205-209.

12. O'Brien P.M.S., Selby C. and Symonds E.M. (1980): Progesterone, fluid, and electrolytes in premenstrual syndrome. Br. Med. J., (280) 6224: 1161-1163

13. Och w., Smolka M., Mariakz. and Koziorow sk ..(2000) : Correlation of steroidal secptors and growth factors expression with peritimoral edem a accompanying cerebral reoplasms. Nevrol Neurochir ., Pol .; 34:91-101.

14. Okatani Y., Okada M. and Sagara Y. (1994): Stimulation of prolactin secretion by melatonin is not mediated by opioids. Horm-Res., 41(1): $38-42$.

15. Okatani Y. and Sagara Y. (1993): Role of melatonin in nocturnal prolactin secretion in women with normoprolactinemia and mild hyperprolactinemia. Am. J. Obstet. Grynecal., 168: 854 - 861.

16. Parry B.L, (1997): Psychobiology of premenstrual dysphoric disorder Seminars in Reproductive Endocrinology, 15(1): 55 -68.

17. Parry B.L., Berga S.L., Mostofi N., Klauber M.R. and Resnick A. (1997): Plasma melatonin circadian rhythms during the menstrual cycle and after light therapy in premenstrual dysphoric disorder and normal control subjects. J. Biological Rhythms, 12(1): 47 -64.

18. Parry B.L., Udell C., Elliott J.A., Berga S.L., Klauber M.R., Mostofi, N., Leveau B. and Gillin J.C. (1997): Blunted phase-shift responses to morning bright light in premenstrual dysphoric disorder. J. Biological Rhythms, 12(5): 443 -456.

19. Reiter R.J. (1989): The pineal gland. DeGroot's Endocrinology. Vol. $2^{\text {nd }}$ ed DeGroot, L.J. (ed) p. 240.
20. Reiter R.J. (1991): Pineal melatonin: Cell biology of its synthesis and of its physiological interactions. Endocr. Rev., 12: 151-180.

21. Reppert S.M., Weaver D.R., Rivkees S.A. and Stopa E.G.(1988): Putative melatonin receptors in a human biological clock Science, 242: 78-81.

22. Rubinow D.R. and Schmidt P.J. (1992): Premenstrual syndrome: a review of endocrine studies. Endocrinologist, 2: 47.

23. Sandyk R., Anastasiadis P.G., Anninos P.A. and Tsagas N. (1992): Is the pineal gland involved in the pathogenesis of endometrial carcinoma. Int.J. Neurosci., 62(1-2):89-96.

24. Shwartz D. (1980): Flammarion Medecine- Sciences Press, $3^{\text {rd }}$ edition-Paris. .

25. Silman R. (1991): Melatonin and the human gonadotrophin-releasing hormone pulse generator.J. Endocrinol., 128: 7-11.

26. Sirotkin A.V. (1994): Direct influence of melatonin on steroid, nonapeptide hormones, and cyclic nucleotide secretion by granulosa cells isolated from porcine ovaries. J. Pineal. Res., 17(3): 112 -117.

27. Su T.P., Schmidt P.J. and Danaceau M.A. (1997): Fluoxetine in the treatment of premenstrual dysphoria. Neuropsycho-pharmacology, 16: 346-356.

28. Taylor J.W. (1979); Plasma progesterone, estradiol 17ß and premenstrual symptoms. Acta Psychiatrica Scandinavica, 60: $76-86$.

29. Terzolo M., Revelli A., Guidetti D., Piovesan A., Cassoni P., Paccotti P., Angeli A. and Massobrio M. (1993): Evening administration of melatonin enhances the pulsatile secretion of prolactin but not of LH and TSH in normally cycling women. Clin. Endocrinol. Oxf., 39(2): 185 -191.

30. Yashkov Y.L., Vinnitsky L.I., Poroykova M.V. and Vorobyova N.T. (2000) : Some hormonal changes before and after vertical banded gastroplasty for severe obesity. Obes. Surg., 10:48-53. 
القياسات المناعية الإشعاعية للتغير ات الهرمونيه المصاحبة لمشاكل الثية

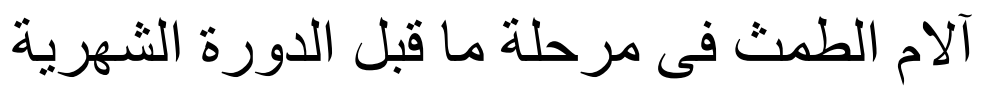
"رجب حسنى اليمانى ـ** مها غازى سليمان الطان

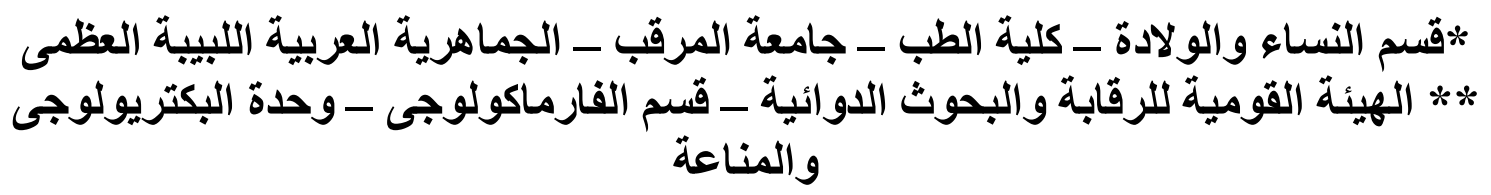
التغير ات العصبية الهرمونية النى تصاحب المرضى الذين يعانون الام ما قبل الدورة

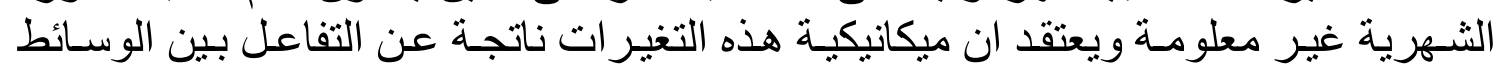

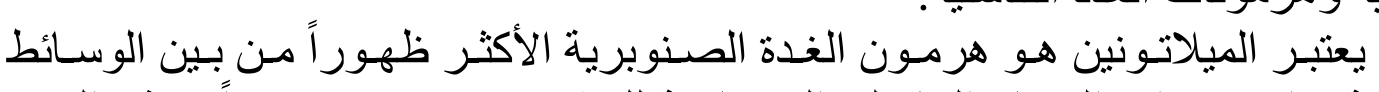

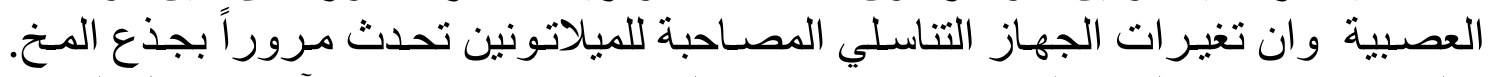

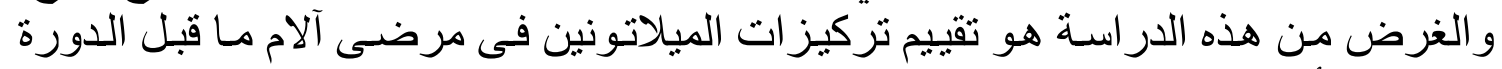

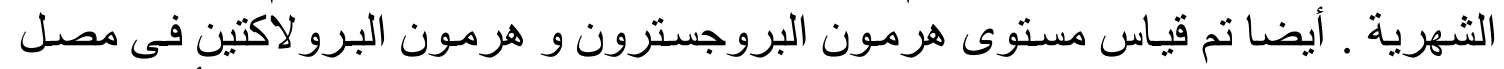

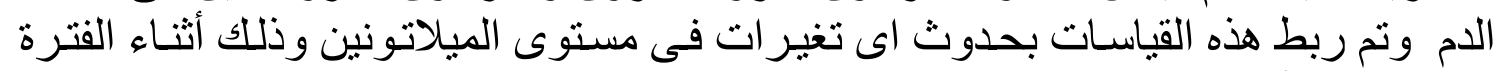

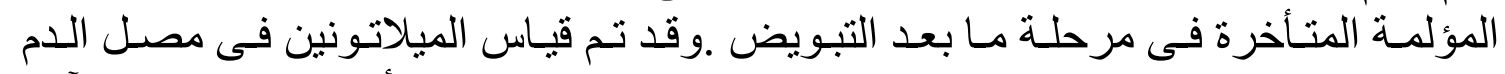

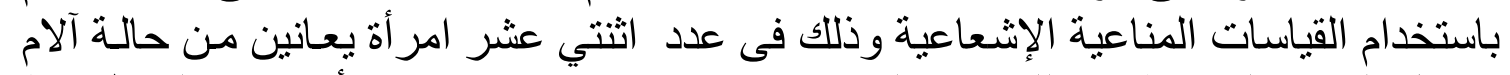

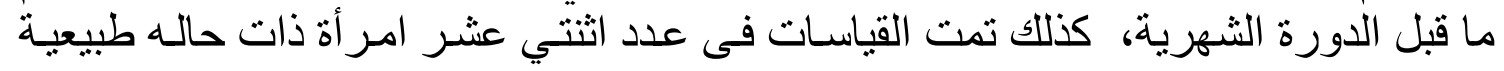

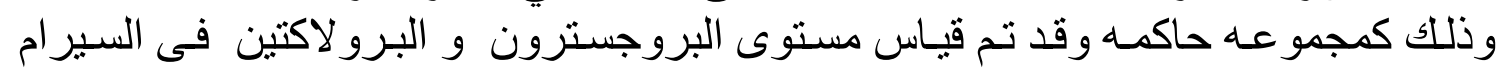

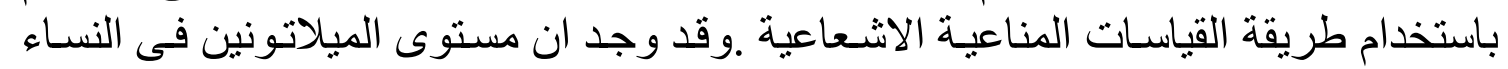

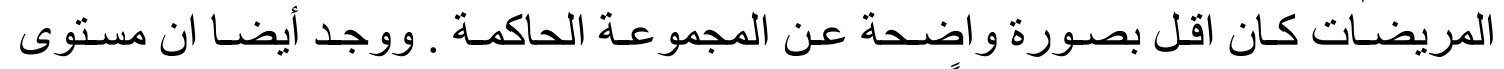

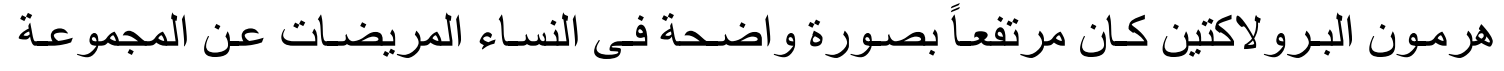

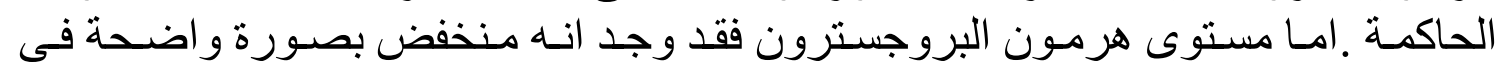
المجموعة المريضة عن المجمو عاكة الحاكمة.

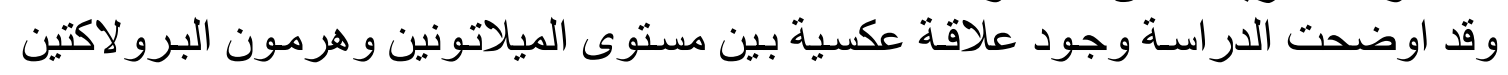

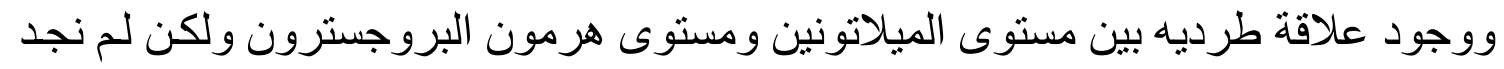

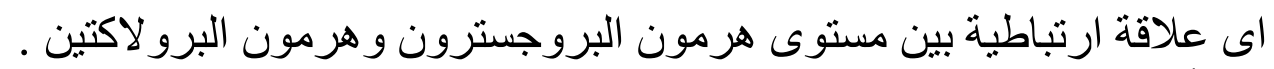

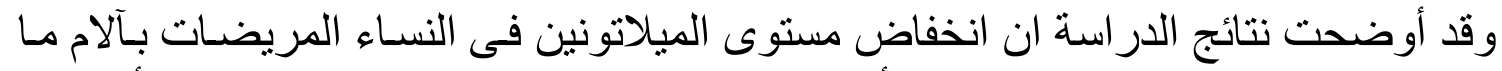

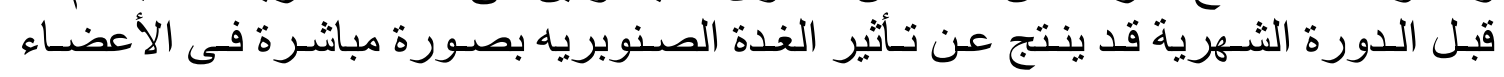

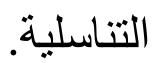

